Original Research Paper

\title{
Assessment of Knowledge, Attitude and Practices of Onchocerciasis Prevention and Control in Becho Woreda, Illu Ababora, Oromia Regional State, South West Ethiopia
}

\author{
${ }^{1}$ Masresha Leta Serbesa, ${ }^{2}$ Maleda Tefera and ${ }^{3}$ W/Michael Moroda Burayu \\ ${ }^{1}$ Midwifery, Harar Health Science College, Ethiopia \\ ${ }^{2}$ Nursing and Midwifery, Haramaya University, Ethiopia \\ ${ }^{3}$ Nursing, Harar Health Science College, Ethiopia
}

Article history

Received: 20-12-2018

Revised: 22-04-2019

Accepted: 04-05-2019

Corresponding Author:

Masresha Leta Serbesa

Midwifery, Harar Health

Science College, Ethiopia

Email: masreshaleta3@gmail.com

\begin{abstract}
Onchocerciasis is a filarial disease caused by onchocerca volvulus and transmitted by a black fly. Onchocerciasis is a killer of livestock and wild animals so Onchocerciasis prevention and control is helpful for health planners and health educators providing basic information to focus on its prevention and control. The objective of this study was to assess the knowledge, attitude and practice of onchocerciasis prevention and control in Becho woreda, Illu Ababora, Oromia regional state, south west Ethiopia, 2018. Community based cross sectional study design was employed through systematic sampling technique. The data were collected from every seven houses after randomly selecting the first house from 1 to 7 until calculated sample size reached. A total of 322 households included in the study. A structured questionnaire was used for gathering the data. Data was coded, entered and analyzed by using SPSS version 16. Out of 322 respondents; 177(59\%) were male and $123(41 \%)$ were female. The response rate was 300(93\%) and the age of respondents ranged from 18-60 years and the majority were $26-45$ years with the mean age of 31 years. The study showed that only 59(19.7\%) of the total respondents knew the right cause of onchocerciasis and majority of them 233(77.7\%) responded that black fly is the cause of the disease. Of the study population, $66 \%$ had poor knowledge, $4.7 \%$ had unfavorable attitude and $77.3 \%$ of them had unsafe practice. As in the result, the study undergone on onchocerciasis prevention and control program showed that; of the study population, $66 \%$ had poor knowledge, $4.7 \%$ had unfavorable attitude and $77.3 \%$ of them had unsafe practice.
\end{abstract}

Keywords: Knowledge, Attitude, Practice, Onchoserciasis

\section{Introduction}

Onchocerciasis (River blindness) is a filarial disease caused by onchocerca volvulus (O.Volvulus) and transmitted by a black fly (simulium). the breeding site of the fly is in rivers and streams. Hence, transmission is most intense in the river valley and the disease is most severe on those communities who reside near the rivers. Onchocerciasis is endemic in many tropical countries mainly in the equatorial region of Africa (WBA, 2013).
Currently, it is estimated that 7.4 million persons are at risk of onchocerciasis and more than 3 million are infected. The main symptoms of the disease is dermal (skin) manifestations that are characterized by disabling intense itching and thickening of the skin, hanging groin and blindness.

The occupation site such as farming and fishing were established to be related with the more exposure and thus high prevalence. The risk behaviours however would vary from culture to culture and with different socio economic situations (Aikin et al., 2010). 
Onchocerciasis is a killer of livestock and wild animals. Infection can cause severe itching of the skin, eye lesions and blindness. It is the world's second leading infection cause of blindness (Abiose, 1998).

More than 120 million people in 37 countries in Africa, Latin America, Yemen and Saudi Arabia are at risk of acquiring the disease. The disease infected over 6.5 million people that suffer from severe provirus, 500,000 are seriously visually impaired and 270,000 are blind (Adoye et al., 2010).

However in areas where transmission is interrupted with ivermectine, it can recur if ivermectine treatment is stopped prematurely. For example, in the mesoendemic Coruba river basin in the Guinea Bissau, civil unrest in 1997 resulted in the suspension of an intensive quarterly ivermectin distribution program after five years of operations. Despite the prevalence levels having fallen in the basin near to zero in 1996 after 20 rounds of treatment, evaluation carried out four years after the disruption of the program showed that recrudescence of infection has occurred. Thus, even the setting transmission may be interrupted, it will likely resume if interventions are healed before the entire duration of the life span of adult $O$.Volvulus worm (WBA, 2013).

Nearly one and half million cases of Onchocerciasis are estimated to exist in Ethiopia especially in South West in an area of about 300,878 square kilometers; the population at risk of infection is estimated to be 7.3 million. The disease affects population in habituating the fertile area of the country and discourages development schemes due to decrease force and decline individual productivities which result increase of dependency and poverty (Wogu and Okaka, 2008; Yirga et al., 2008). one study done in Edo State, Nigeria about Knowledge, attitude and perception toward Onchocerciasis and its treatment with ivermectin suggested that adequate knowledge has a significant impact on the reduction of prevalence of onchoseciasis even if majority of them perceived various symptom of onchocerciasis such as itching, nodules, leopard skin, lizard skin and ocular lesion as separate diseases.

Some people were given ivermectin during the yearly single-dose treatment, only actually took the drug while the rest opted for local traditional method of treatment. The study done at Nigeria suggested that, the community need to be educated and sufficiently mobilized to appreciate onchocerciasis as a health problem so as to positively change their attitude, perception and level of awareness of the disease and the efficacy of ivermectin treatment. That in turn should greatly increase the distribution, coverage and acceptance level of ivermectin used for the control of onchocerciasis in the community.

Although identifying status of the major Knowledge, Attitude and Practice (KAP) of the people has strongly associated with infection and is necessary to guide for specific and targeted preventive activities (WHO, 1995; Edungbola, 1991) there was no research done in the study area related to onchocerciasis. In our study area the prevalence of knowledge toward onchoserciasis prevention and control to be $19.7 \%$.

Therefore, the aim of this study was to assess KAP of Onchocerciasis prevention and control in Becho woreda which helped health planners and health educators providing basic information to focus on its prevention, control and also provided as a baseline data on the awareness and practice of Onchocerciasis prevention and control for the study area.

\section{Materials and Methods}

A community based cross-sectional study was employed among Becho district residents from April 20 to May 20, 2018 among 322 residents using a multistage sampling procedure was employed in this study. First stratified sampling procedure was used to divide the source population into five sub-populations (strata), are the primary sampling units.

Then using simple random sampling 5kebeles was selected independently and randomly. Hence from 16 kebeles Tubi, Seki, Bake, Yemi and Bokoji were randomly selected by using lottery method. The study was conducted in Becho district, Ilu Ababor zone of Oromia regional state, south west Ethiopia. The woreda situated at a distance of $622 \mathrm{KM}$ away from the capital city of the country, Addis Ababa.

Becho district is one of the districts found in Ilu Ababor administrative Zone and has 17 kebeles, with a total population of 25,800 (ECSA, 2007). Of which, 13,100 are male and the rest 12,700 are female. The total number of households in the woreda is 1238 (ECSA, 2007). Regarding health infrastructure, the woreda has two governmental functional health centers, 16 health posts and 3 private clinics. Educational wise there are 31elementary schools and 2 high schools and one preparatory school. Majority of the district population earn their likely hood by the product of agriculture, especially coffee plantation and processing.

Data was collected by using structured questionnaire by 5 Health extension workers. The data collectors was given an orientation on how to collect data using consent form and structured questionnaire as per scheduled work plan. 
The quality of data was primarily a standard questioner developed and translated to locally dominant language which is Afan Oromo. And also orientation of data collectors was conducted. Finally to know the characteristics of questionnaires a pre-test was carried out in randomly selected $5 \%$ of the total sample size which is $21 \mathrm{HHs}$ two days before the actual data collection day. These HHs are not in the current study area but similar in many aspects. Thus, based on the findings of the pre-test the investigator has made necessary modification. Additionally, close supervision of data collectors was undertaken.

After data collection for quantitative data, after checking the completeness of questionnaires, the data was processed coded, entered and analyzed by using software statistical packages for social sciences version 16. The presentation was prepared and summated by tabulation, frequency, graphs and pie chart.

Quality was maintained by careful design, translation and retranslation of the questionnaire, proper orientation of the interviewers and supervisors, close supervision of the data collecting procedures, proper categorization and coding of the data and checking for completeness and internal consistency was made.

Before undergoing the study, letter of cooperation was written from Harar Health science college to the concerned bodies and permission was taken from concerned authorities. Consent was obtained from the respondents and confidence was secured.

\section{Results}

\section{Socio Economic and Demographic Characteristics}

About half; $177(59 \%)$ of the respondents were male and $123(41 \%)$ of them were female; from the random community sample of 322 , I was able to attain response rate of $300(93 \%)$ and the age of respondents ranged from 18-60 years and the majority were 26-45 years. More than half; 192(64\%) of household family size were between six to eight individuals and the least $7(3 \%)$ were eight and above individuals and almost all $291(97 \%)$ of the respondents were belonged to Oromo ethnic group and the remaining respondents were belonged to Amhara ethnic group 9(3\%), farmers $260(86.7 \%)$, married 298(99.3\%) and followers of orthodox $161(53.7 \%)$ religion. Among the study subjects $20(6.7 \%)$ were illiterate, $3(1 \%)$ can read and write, 164(54.7) were learnt elementary school and the rest of participants $113(37.7 \%)$ have high school and above educational levels and $164(54.7 \%)$ of the respondents earned household average monthly income ranged from 100-400 (Table 1).

The study showed that only $59(19.7 \%)$ of the total respondents knew the right cause of onchocerciasis and majority of them $233(77.7 \%)$ responded that black fly is the cause of the diasese; this indicates that they lacked adequate knowledge on the causes of onchocerciasis.

\section{Knowledge on Prevention and Control of Onchocerciasis}

The study indicates that $173(57.7 \%)$ of the study participants knew that onchocerciasis is communicable disease which can be transmitted from person to person and $145(48.3 \%)$ knew that the disease is prevented. Even though majority of them knew onchocerciasis is communicable disease, they lacked adequate knowledge on the right mode of transmission and different methods of onchocerciasis prevention and control.

Among the study participants; only 136(45.3\%) of them knew the right site of breeding places of black flies and $154(51.3 \%)$ of the respondents understood in wrong way about the breeding site of black flies by stating stagnant water.

Among the study population; $180(60 \%)$ of them had information about onchocerciasis from health extension workers, 68(22.7\%) from health center and $45(15 \%)$ of them do not have any information about the disease.

The study showed that participants' attitudes were positively correlated towards prevention and control of oncchocerciasis. Majority, $91.3 \%$ of them knew that the final risk of onchocerciasis is blindness and death.

\section{Practice on Prevention and Control of Onchocerciasis}

Although, majority of the study participants had favorable attitude towards prevention and control of Onchocerciasis, they have not practiced well or very poor practice about the disease prevention and control. Out of 300 study subjects, only 36(12\%) of them practiced to wear protective clothes when they are doing around fast flowing rivers; only $77 \%$ of them are taking Ivermectine for Onchocerciasis prevention. Fifteen point seven percent (15.7\%) of respondents thought others to wear protective clothes when they are doing around fast flowing rivers and $295(98 . \%)$ of the study subjects have practiced to take Ivermectine along with their family members for prevention and control of Onchocerciasis. 
Table 1: Frequency distribution of socio-economic and demographic characteristics of respondents

\begin{tabular}{|c|c|c|}
\hline & Frequency & Percen \\
\hline \multicolumn{3}{|l|}{ Sex of respondents } \\
\hline Male & 177 & 59.0 \\
\hline Female & 123 & 41.0 \\
\hline Total & 300 & 100.0 \\
\hline \multicolumn{3}{|l|}{ Age of the respondents } \\
\hline $18-25$ & 19 & 6.3 \\
\hline $26-35$ & 134 & 44.7 \\
\hline $36-45$ & 121 & 40.3 \\
\hline $46-55$ & 16 & 5.3 \\
\hline $56-65$ & 10 & 3.3 \\
\hline Total & 300 & 100.0 \\
\hline \multicolumn{3}{|c|}{ Family size of the respondents } \\
\hline $1-2$ & 37 & 12.3 \\
\hline $3-5$ & 192 & 64.0 \\
\hline $6-8$ & 64 & 21.3 \\
\hline$>8$ & 7 & 2.3 \\
\hline Total & 300 & 100.0 \\
\hline \multicolumn{3}{|l|}{ Marital status } \\
\hline Single & 1 & 0.3 \\
\hline Married & 298 & 99.3 \\
\hline Divorce & 1 & 0.3 \\
\hline Total & 300 & 100.0 \\
\hline \multicolumn{3}{|l|}{ Religion } \\
\hline Orthodox & 161 & 53.7 \\
\hline Muslim & 114 & 38.0 \\
\hline Protestant & 24 & 8.0 \\
\hline Others & 1 & 0.3 \\
\hline Total & 300 & 100.0 \\
\hline \multicolumn{3}{|c|}{ Ethnicity of the respondents } \\
\hline Oromo & 291 & 97.0 \\
\hline Amhara & 9 & 3.0 \\
\hline Total & 300 & 100.0 \\
\hline \multicolumn{3}{|l|}{ Occupational status } \\
\hline Farmer & 260 & 86.7 \\
\hline Merchant & 14 & 4.7 \\
\hline Government employer & 10 & 3.3 \\
\hline Student & 1 & 0.3 \\
\hline Daily labourer & 14 & 4.7 \\
\hline Others & 1 & 0.3 \\
\hline Total & 300 & 100.0 \\
\hline \multicolumn{3}{|l|}{ Educational status } \\
\hline Illiterate & 20 & 6.7 \\
\hline read and write & 3 & 1.0 \\
\hline grade $1-4$ & 29 & 9.7 \\
\hline grade $5-8$ & 135 & 45.0 \\
\hline grade $9-10$ & 107 & 35.7 \\
\hline grade $11-12$ & 4 & 1.3 \\
\hline$>12$ & 2 & 0.7 \\
\hline Total & 300 & 100.0 \\
\hline \multicolumn{3}{|c|}{ Average monthly household income (in birr) } \\
\hline$<100$ & 95 & 31.7 \\
\hline $100-400$ & 164 & 54.7 \\
\hline $401-700$ & 30 & 10.0 \\
\hline $701-1000$ & 4 & 1.3 \\
\hline$>1000$ & 7 & 2.3 \\
\hline Total & 300 & 100.0 \\
\hline
\end{tabular}


Table 2: Respondents' knowledge on causes of onchocerciasis

\begin{tabular}{lcr}
\hline Causes of onchocerciasis & Frequency & Percent \\
\hline Hereditary & 3 & 1.0 \\
Mosquitoes' bite & 1 & 0.3 \\
Black fly (simulium) bite & 233 & 77.7 \\
Parasite (O.volvulus) & 59 & 19.7 \\
Don't know & 4 & 1.3 \\
Total & 300 & 100.0 \\
\hline
\end{tabular}

Table 3: Respondent's knowledge on the transmission and prevention of onchocerciasis

\begin{tabular}{|c|c|c|c|c|c|c|}
\hline \multirow[b]{2}{*}{ Knowledge of respondents } & \multicolumn{2}{|l|}{ Yes } & \multicolumn{2}{|l|}{ No } & \multicolumn{2}{|c|}{ Total } \\
\hline & № & $\%$ & № & $\%$ & № & $\%$ \\
\hline Onchocerchiasis is communicable & 173 & 57.7 & 127 & 42.3 & 300 & 100 \\
\hline Onchocerchiasis is preventable & 145 & 48.3 & 155 & 51.7 & 300 & 100 \\
\hline
\end{tabular}

Table 4: Respondents' knowledge on the breeding site of black flies

\begin{tabular}{lrr}
\hline Breeding site of black flies & Frequency & Percent \\
\hline Dirty places & 5 & 1.7 \\
Stagnant water & 154 & 51.3 \\
Fast flowing water & 136 & 45.3 \\
Forest & 5 & 1.7 \\
Total & 300 & 100.0 \\
\hline
\end{tabular}

\section{Knowledge on the Cause of Onchocerciasis}

From the total respondents toward Knowledge on the cause of onchocerciasis, majority of them $(77.7 \%)$ responded that Black fly bite was the main cause for the occurence of Onchocerciasis (show Table 2).

\section{Knowledge on the Transmission and Prevention of Onchocerciasis}

With regard to respondents knowledge toward the transmission and prevention of onchocerciasis , all of the respondents had knowledge on the prevention and transmission of onchocerciasis (show Table 3).

\section{Respondents' Knowledge on the Breeding Site of Black Flies}

Majority of the respondents (51.3\%) had a knowledge of stagnant water was the main breeding site for black flies (show Table 4).

\section{Discussion}

Majority of the study participants were familiar with onchocerciasis, this is probably due to endemicity of the disease in the study area. In the study area, the disease is called "fileeriyaa". However many authors believe that low level of knowledge and practices of the peasants of rural Africa predispose them to infection (Dadzie et al., 2008). The health impact of onchocerciasis has no great deal of attention in most endemic area of the country (Onchocerciasis Control Program, 2010); for instance, of 14 woredas found in
Illu Ababora administrative zone, onchocerciasis prevention and control program had implemented only in few woredas.

In this study, from 300 subjects, only 59(19.7\%) knew about the aetiology (causative agent) of the disease and the majority of them responded with wrong answers about the cause of the disease which is consistent with the findings of other studies (Wogu and Okaka, 2008; Wagbatsoma and Aisien, 2004). On the other hand, majority of respondents associated the causative agent of the disease with the bite of black flies which is comparable to the finding of the study conducted in Bebeka, southwest Ethiopia (Wagbatsoma and Aisien, 2004). Similarly; in this study, majority of the study population responded with at least more than one wrong answers about mode of transmission of onchocerciasis which is consistent with the findings of the study conducted in Bebeka southwest Ethiopia (Wagbatsoma and Aisien, 2004).

This study showed that $198(66 \%)$ had poor knowledge, 14(4.7\%) unfavourable attitude and 232(77.3\%) unsafe practice towards onchocerciasis prevention and control. Educational status was the factor significantly associated with KAP of study population on control and prevention of onchocerciasis. Generally, in this study majority of the study participants had low level of knowledge about the disease; only 34\% of respondents had good level of knowledge. This finding is also consistent with the findings of the study conducted in Sequa area; Southwest Ethiopia (Center, 2005). Similarly, majority of the study subjects had very poor practice about onchocerciasis prevention and control i.e., only $22.7 \%$ of them had practiced safest way of prevention and control of the disease. 
Inadequate KAP of the study participants towards prevention and control of onchocerciasis is probably due to shortage of health education at community level and CDDs may not be properly trained about the disease. The study also indicates the source of information, $60 \%$ of respondents get from health extension workers and $22.7 \%$ of them from health centre. Thus, restricted source of information influenced the KAP of community towards prevention and control of onchocerciasis.

When the black flies bite a human being, the worm of the fly sheath under the skin and infect the individual. The microfilaria irritates the skin and cause intense itching, skin discoloration and rashes. If the microfilaria enters the eyes, they cause inflammation and irritation, which can cause diminished vision and potential blindness. The disruption of family life and education resulting from the disease directly impacts local economies and long-term development (Center, 2005).

If there is adequate distribution of ivermectine drug to a highly endemic areas of the community, has a wider contribution of reduction of morbidity and transmission of onchocerciasis.

Educational activities, developed with careful consideration of community attitudes, should promote positive treatment seeking behaviour while simultaneously addressing local reservations about the control effort. A study done at Guatemala on KAP toward ivermectin utilization on the prevention of Onchocerciasis among 145 households of five endemic communities revealed that $100 \%$ of them had heard about the disease of filaria was the major cause for the occurrence of blindness. Around ninety -five percent of them suggested that surgery was the only way for curing the condition. Relatively few of the respondent (39\%), suggested that filaria was caused by the worm. Half of the respondent explained that the disease was caused by the bite of the insect. However; few respondents (12\%), unable to differentiate onchocerciasis from a bad cold disease. The study recommends that, assist long-term acceptance of a national chemotherapy initiative helpful against onchocerciasis prevention and control in Guatemala (Roberto et al., 1981).

Of the total respondents, $93 \%$ and $53 \%$ of respondent were agreed upon administering Ivermectine to pregnant woman and seriously ill person and children under 5 years of age with less than $90 \mathrm{~cm}$ long and less than $15 \mathrm{~kg}$ weigh respectively. Additionally, $35 \%$ of them agreed that the breeding site of black flies are dirty places and stagnant water; about $32 \%$ of them do not know the breeding site of black flies; which is not similar with different literatures which indicate the breeding site of black flies are fast flowing rivers and streams (Roberto et al., 1981).

Regarding the practice of respondents, only $28 \%$ of them had safe practice which is below the operational term $(<60 \%)$; and majority $72 \%$ of study participants were not having safe practice for prevention and control of onchocerciasis.

\section{Recommendation}

Recommendation goes to ministry of health in order to Develop Health education materials should focus on causative agent, mode of transmission and prevention of onchocerciasis information in order to ensure better understanding of individuals about the disease.

\section{Acknowledgment}

We would like to extend appreciations to individuals who involved in data collection and Becho woreda community as well those study participants who willingly gave us all the information we needed without any reservation.

\section{Availability of Data and Materials}

This is a research article

\section{Competing Interests}

We declare that we have no competing interests.

\section{Authors' Contribution}

Masresha Leta Serbesa, Maleda Tefera and W/Michael Moroda Burayu: Conceived the study, participated in the design, data analysis and interpretation of the result.

Masresha Leta Serbesa: Involved in data acquisition, writing the draft manuscript as well as making all the changes as suggested by the coauthors.

Maleda Tefera and W/Michael Moroda Burayu: Critically reviewed the manuscript. All authors read and approved the manuscript.

\section{References}

Abiose, A., 1998. Onchocercal eye disease and the impact of Mectizan treatment. Ann. Trop. Med. Parasitol., 92: 511-522. PMID: 9861263

Adoye, A.O., A.A. Ashaye and O.H. Onakpoya, 2010. Perception and attitude of people toward onchcerciasis (River Blindness) in south west Nigeria. Middle East Afr. J. Opthalmol., 17: 310-314. DOI: 10.4103/0974-9233.71594

Aikin, A.D.G., N. Unwin, C. Agyemang, P. Allotey and C. Campbell et al., 2010. Tackling Africa's chronic disease burden: From the local to the global. Globalizat. Health, 6: 5-5.

DOI: $10.1186 / 1744-8603-6-5$ 
Center, T.C., 2005. Summery 2004 program review for the lions-carter center sight first river blindness programs. Atlanta GA.

Dadzie, Y., M. Neira and D. Hopkins, 2008. Final report of the conference on the eradicability of Onchocerciasis. Filaria J., 2: 2-2. DOI: 10.1186/1475-2883-2-2

ECSA, 2007. Ethiopian Central Stastical Agency.

Edungbola, L.D., 1991. Onchocerciasis control in Nigeria. Parasitol. Today, 7: 97-99. DOI: $10.1016 / 0169-4758(91) 90165-\mathrm{K}$

Onchocerciasis Control Program, 2010. http:/www.who.Int/countries/eth/news/2006/monitor ing. cdti/en/index.html

Roberto, W., M.S. Tatichef and H. Grawehte, 1981. Blindness in korcha district in Illubabor, Southwest Ethiopia. Med. J.

Wagbatsoma, V.A. and M.S.O. Aisien, 2004. Knowledge, attitude and perceptions of Onchocerciasis in a hyper-endemic community of Edo State, Nigeria. Afr. J. Clin. Exper. Microbiol., 5: 236-237. DOI: 10.4314/ajcem.v5i3.7384

WBA, 2013. The global burden of disease: Main findings for sub-Saharan Africa. The World Bank in Africa.

WHO, 1995. Onchocerciasis and its control. Report of a WHO expert committee on onchocerciasis control. World Health Organ Tech. Rep. Ser., 852: 1-104.

Wogu, M.D. and C.E. Okaka, 2008. The knowledge, attitude and perception of onchocerciasis and ivermectin treatment by the people in Okpuje, Edo State, Nigeria. Int. J. Biomed. Health Sci., 4: 122-23.

Yirga, D., K. Woldemichael, M. Wondafrash, W. Kassahun and K. Deribe, 2008. Knowledge and belief about cause and prevention of onchocerciasis in Bebeka, Southwest Ethiopia. Ethiop J. Health Sci., 18: 66-68.

\section{List of Acronyms and Abbreviation}

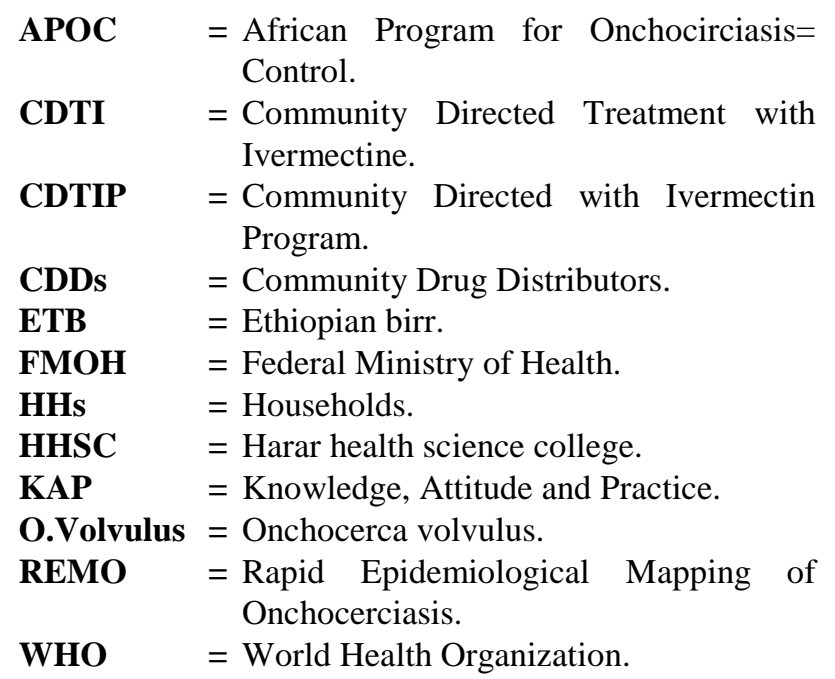

